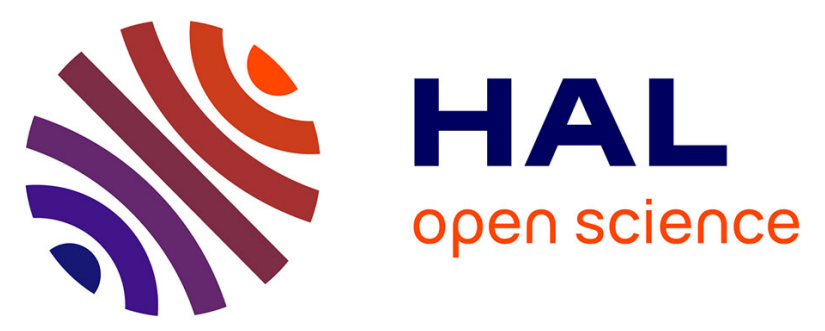

\title{
Core Cross-Linked Amphiphilic Star-Block Copolymers with (Meth)acrylic Acid Shells Prepared by Atom Transfer Radical Polymerization
}

Andrea Carletto, Andrés Fernando Cardozo Perez, Raffaella Suriano, Eric Manoury, Stefano Turri, Rinaldo Poli

\section{To cite this version:}

Andrea Carletto, Andrés Fernando Cardozo Perez, Raffaella Suriano, Eric Manoury, Stefano Turri, et al.. Core Cross-Linked Amphiphilic Star-Block Copolymers with (Meth)acrylic Acid Shells Prepared by Atom Transfer Radical Polymerization. Israel Journal of Chemistry, 2012, Controlled Radical Polymerizations: Wolf Prize for Krzysztof Matyjaszewski, 52 (3-4), pp.328-338. 10.1002/ijch.201100125 . hal-02909429

\section{HAL Id: hal-02909429 \\ https://hal.science/hal-02909429}

Submitted on 3 Mar 2021

HAL is a multi-disciplinary open access archive for the deposit and dissemination of scientific research documents, whether they are published or not. The documents may come from teaching and research institutions in France or abroad, or from public or private research centers.
L'archive ouverte pluridisciplinaire HAL, est destinée au dépôt et à la diffusion de documents scientifiques de niveau recherche, publiés ou non, émanant des établissements d'enseignement et de recherche français ou étrangers, des laboratoires publics ou privés. 


\title{
Core cross-linked amphiphilic star-block copolymers with (meth)acrylic acid shells prepared by atom transfer radical polymerization
}

Andrea Carletto, ${ }^{\mathrm{a}, \mathrm{b}}$ Andrés F. Cardozo, ${ }^{\mathrm{a}}$ Raffaella Suriano, ${ }^{\mathrm{b}}$ Eric Manoury, ${ }^{\mathrm{a}}$ Stefano Turri, ${ }^{\mathrm{b}}$ Rinaldo Poli*,a,c

${ }^{a}$ CNRS; LCC (Laboratoire de Chimie de Coordination); Université de Toulouse; UPS, INP; F31077 Toulouse, France ; 205, route de Narbonne, F-31077 Toulouse, France; Tel: (+) 44561553003 ; Fax: (+) 33-561553003; E-mail: poli@lcc-toulouse.fr

${ }^{b}$ Dipartimento di Chimica, Materiali e Ingegneria Chimica "Giulio Natta», Politecnico di Milano, Piazza L. da Vinci 32, 20133 Milan, Italy

${ }^{c}$ Institut Universitaire de France, 103, bd Saint-Michel, 75005 Paris, France

Dedicated to Krzysztof Matyjaszewski on the occasion of his Wolf Prize

\begin{abstract}
Core cross-linked amphiphilic star-block copolymers were prepared by hydrolysis of the outer shell of star-block copolymers prepared using copper mediated atom transfer radical polymerization (ATRP). In an arm-first approach, linear poly(tert-butyl methacrylate) macroinitiators (PtBMA-Cl) were extended with styrene to yield PtBMA- $b-\mathrm{PS}-\mathrm{Cl}$ and then cross-linked with divinylbenzene (DVB) in order to yield (PtBMA- $b$-PS) $)_{\text {arms }}-$ PDVB $_{\text {core }}$ star-block copolymers. Then, PMAA- $b$-PS block and (PMAA-PS) arms PDVB $_{\text {core }}$ star-block copolymers were obtained by hydrolysis of the PtBMA blocks in both linear and cross-linked copolymers, as confirmed by ${ }^{1} \mathrm{H}$ NMR analyses. The amphiphilic character of these copolymers was confirmed by solubilisation in water. Several factors affecting the polymer aggregation and solubility such as the length, the composition of the arms and the catalyst used were studied. An acrylate analogue i.e. (PAA- $b$-PS) $)_{\text {arms }}-\mathrm{PDVB}_{\text {core }}$ was also prepared for comparison purposes. Atomic Force Microscopy (AFM) and Differential Scanning Calorimetry (DSC) were used to elucidate the morphology and the thermal behaviour of the star-block copolymers.
\end{abstract}


Keywords: ATRP, amphiphilic polymers, core-shell polymers, polymerization, polymers, starblock copolymers

\section{Introduction}

Using controlled radical polymerization techniques, it is now possible to engineer highly sophisticated polymer architectures. ${ }^{[1]}$ For instance, block copolymers are readily assembled by sequential addition of the desired monomers in two or more separate polymerization steps, where the polymer resulting from the $\mathrm{n}^{\text {th }}$ step serves as macroinitiator for the assembly of the $(n+1)^{\text {th }}$ block.

Among various block copolymers, those having amphiphilic character are particularly interesting for applications that entail compatibilization with an aqueous environment, especially for biomedical applications such as vectors for drug delivery. ${ }^{[2-3]}$ The self assembly of amphiphilic block copolymers into micelles allows transporting a hydrophobic cargo through blood and across membranes in the body. ${ }^{[4]}$ A problem of self-assembled micelles, however, is their equilibrium with the free linear polymers, under the thermodynamic constraint of the critical micellar concentration. It is of potential interest, and not only for biomedical applications, to covalently link the linear chains at the core and create a star-like structure, with each arm being the amphiphilic block copolymer, in order to create a "unimolecular" micelle, for which equilibrium is no longer possible with the free arms.

Multiple arm stars have been assembled by either the core-first ${ }^{[5]}$ or the arm-first ${ }^{[6]}$ method, with the initiating (in the former approach) or terminating (in the latter one) reagent being either a well defined multifunctional molecule (when stars having a controlled number of arms is desired) or a divalent monomer, resulting in the formation of a nanogel. The latter method yields stars with a distribution for the number of arms. Among various controlling techniques, atom transfer radical polymerization (ATRP) has emerged as a preferred method, expecially when using $\mathrm{Cu}$ complexes as catalysts since these are inexpensive and easy to assemble by combination of a simple $\mathrm{Cu}^{\mathrm{I}}$ halide salt and a suitable additive from a wide library of available ligands. ${ }^{[7]}$

In this contribution, we are exploring an arm-first approach for the assembly of star polymers where the inner core is a nanogel generated by the polymerization of a divalent monomer (divinyl benzene) and the arms are amphiphilic blocks, the hydrophilic block being placed on the outer shell. Our strategy consists in assembling I-P $t$ BMA- $b$-PS-X and I-P $t$ BA- $b-$ PS-X linear arms from an I-X initiator by standard ATRP in an organic medium, followed by 
cross-linking with DVB and final hydrolysis of the outer shell to create the final amphiphilic object with PMAA or PAA hydrophilic shells. The strategy is summarized in Scheme 1. The hydrolyzed linear arms have also been generated for comparison.

Relative to the state of the art, which usually explores amphiphilic core-shell particles with relatively short arms, our investigation includes polymers with relatively long arm. In addition, we introduce the shell hydrophilicity through PMAA or PAA chains, instead of the more ubiquitous PEO chains which are characterized by a low LCST in water and therefore become compatible with the organic phase at high temperatures. One of our objectives for future applications is to confine the amphiphilic polymer in the water phase even at relatively high temperatures.

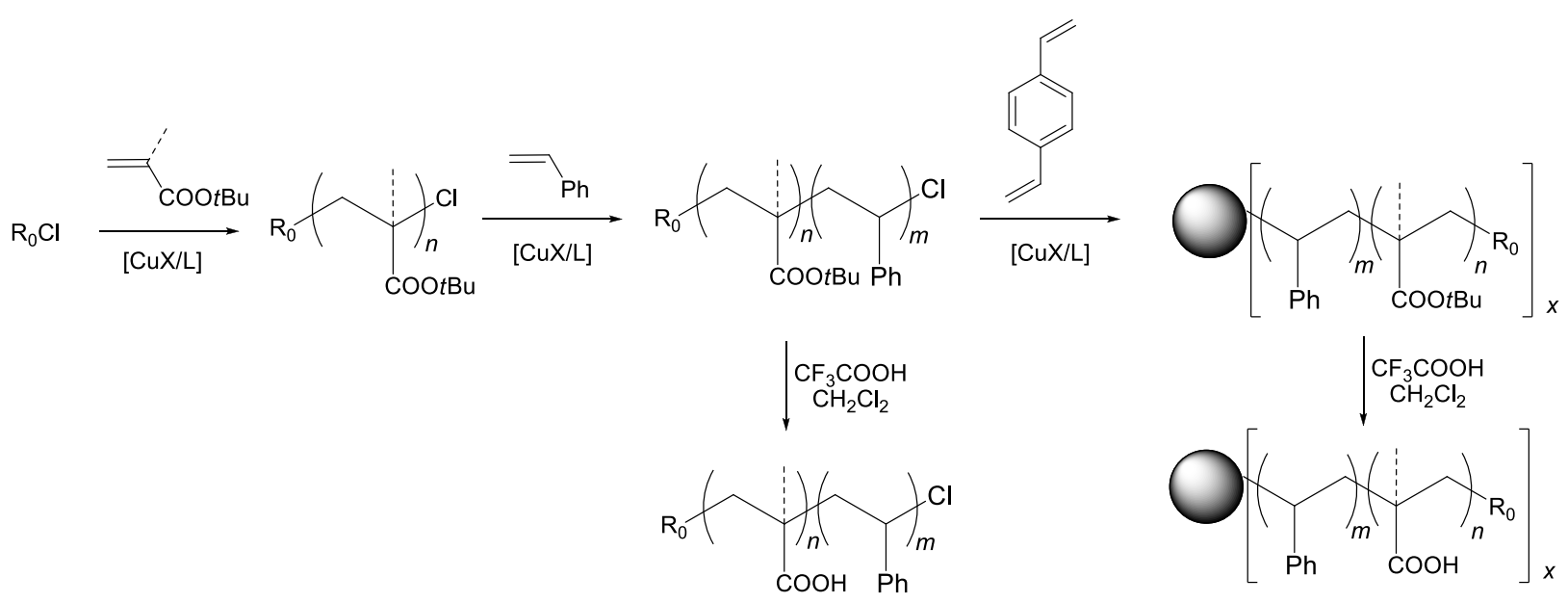

Scheme 1. General strategy for the construction of core cross-linked amphiphilic star-block copolymers.

\section{Results}

\section{(a) Ts-PtBMA-Cl macroinitiator synthesis}

Following a literature protocol, ${ }^{[8]}$ a Cl-terminated PtBMA block was prepared using tosyl chloride as initiator, $\mathrm{CuCl} / \mathrm{PMDETA}$ as catalyst (PMDETA $=N, N, N^{\prime}, N^{\prime}, N^{\prime \prime}$-pentamethyldiethylenetriamine $)$, and toluene as solvent at $80^{\circ} \mathrm{C}(t \mathrm{BMA} / \mathrm{TsCl} / \mathrm{CuCl} / \mathrm{PMDETA}=30: 1: 1: 1)$. The polymerization was quite fast (ca. $89 \%$ conversion in $2.5 \mathrm{~h}$ and well controlled, yielding an

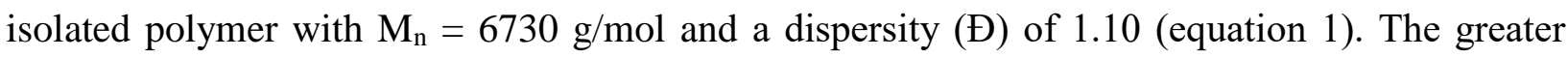
degree of polymerization (46) relative to the initial monomer/initiator ratio, as revealed by SEC, indicates low initiator efficiency. 


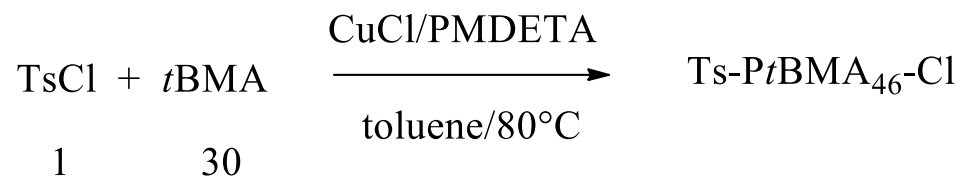

Additional samples of the PtBMA macroinitiator, with number average degree of polymerizations of 30 and 53, were also prepared using $\mathrm{CuBr}$ as catalyst, again with $\mathrm{TsCl}$ as initiator. As known in the literature, ${ }^{[9]}$ the relative affinity of the two halides for copper(I) and carbon is such that $\mathrm{Br}$ should remain on the metal and $\mathrm{Cl}$ on the polymer chain. The obtained $\mathrm{Cl}$ terminated PtBMA macromolecules are summarized in Table 1. Note that, although the polymerization was well controlled in all cases, use of the $\mathrm{CuBr}$ catalyst yielded a narrower molecular weight distribution. After purification, all polymers were white indicating complete removal of the $\mathrm{Cu}$ salt. The ${ }^{1} \mathrm{H}$ NMR spectra allowed an independent verification of the degree of polymerization by chain-end analysis (integration of the methyl group resonance of the tosyl fragment relative to the tert-butyl protons). For instance, the Ts-( $t \mathrm{BMA})_{46}-\mathrm{Cl}$ sample, shown in Figure 1 (top), gave a number average degree of polymerization of 48.5 from the NMR integration.

Table 1. ATRP of $t$ BMA polymers and chain extension with styrene.

\begin{tabular}{|c|c|c|c|c|}
\hline First block & $\begin{array}{l}\mathrm{Mn}_{\mathrm{SEC}} \\
\text { (Đ) }\end{array}$ & Catalyst & Diblock & $\mathrm{Mn}_{\mathrm{SEC}}(\mathrm{D})$ \\
\hline Ts-P $t \mathrm{BMA}_{30}-\mathrm{Cl}$ & $\begin{array}{l}4380 \\
(1.05)\end{array}$ & $\mathrm{CuBr}$ & Ts-P $t \mathrm{BMA}_{30}-b-\mathrm{PS}_{19}-\mathrm{Cl}$ & $6360(1.22)$ \\
\hline \multirow{2}{*}{ Ts-P $t$ BMA $46-\mathrm{Cl}$} & \multirow{2}{*}{$\begin{array}{l}6730 \\
(1.10)\end{array}$} & \multirow{2}{*}{$\mathrm{CuCl}$} & $\mathrm{Ts}_{-} \mathrm{P} t \mathrm{BMA}_{46}-b-\mathrm{PS}_{135}-\mathrm{Cl}$ & $20780(1.16)$ \\
\hline & & & Ts-PtBMA ${ }_{46}-b-\mathrm{PS}_{186}-\mathrm{Cl}$ & $26140(1.10)$ \\
\hline \multirow{3}{*}{ Ts-PtBMA ${ }_{53}-\mathrm{Cl}$} & \multirow{3}{*}{$\begin{array}{l}7730 \\
(1.03)\end{array}$} & \multirow{3}{*}{$\mathrm{CuBr}$} & Ts-PtBMA ${ }_{53}-b-\mathrm{PS}_{13}-\mathrm{Cl}$ & $9120(1.45)$ \\
\hline & & & $\mathrm{Ts}_{\mathrm{P} t \mathrm{BMA}_{53}-b-\mathrm{PS}_{16}-\mathrm{Cl}}$ & $9340(1.42)$ \\
\hline & & & Ts-P $t \mathrm{BMA}_{53}-b-\mathrm{PS}_{97} \mathrm{Cl}$ & $17850(1.25)$ \\
\hline
\end{tabular}




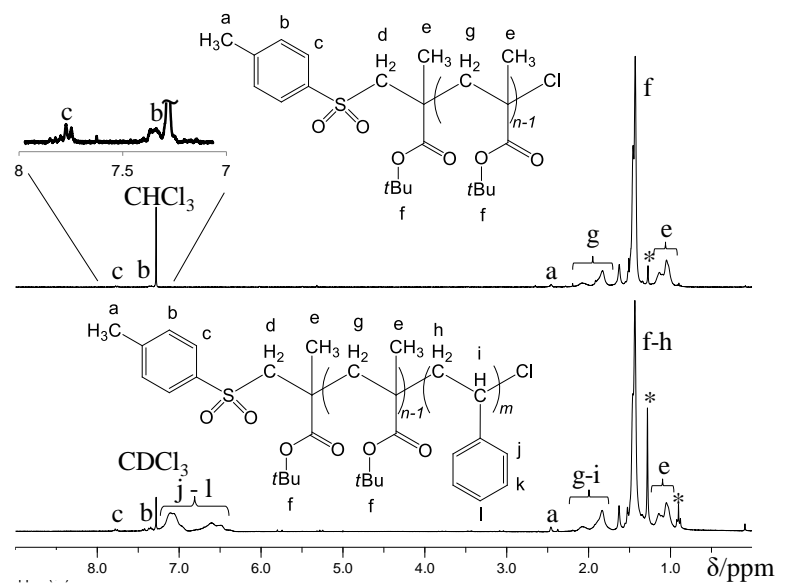

Figure 1. ${ }^{1} \mathrm{H}$ NMR spectra of Ts-P $t \mathrm{BMA}_{46}-\mathrm{Cl}$ (top) and Ts-P $t \mathrm{BMA}_{46}-\mathrm{b}-\mathrm{PS}_{186}-\mathrm{Cl}$ (bottom) in $\mathrm{CDCl}_{3}$. The asterisks (*) indicate residual solvent signals.

\section{(b) Synthesis of Ts-PtBMA-b-PS-Cl diblock macroinitiators}

The above $\mathrm{Cl}$-functionalized $\mathrm{P} t \mathrm{BMA}$ products were used as macroinitiators for the polymerization of styrene under the conditions indicated in the literature, ${ }^{[10]}$ namely using $\mathrm{CuCl} / \mathrm{PMDETA}$ as catalyst and toluene as solvent, at a temperature of $100^{\circ} \mathrm{C}$. In order to limit halogen loss at the chain ends by disproportional coupling, ${ }^{[11]}$ these polymerizations were stopped at low to moderate conversion (no more than $70 \%$ monomer conversion as monitored by gas chromatography), and the products were isolated and characterized by SEC and ${ }^{1} \mathrm{H}$ NMR. Different polymers with different sizes were prepared depending on the initial monomer to macroinitiator ratio. These products are also summarized in Table 1. All the diblock copolymers had a slightly greater dispersity then the precursor Ts-PtBMA-Cl macroinitiator (up to 1.45). Nevertheless, the molecular weight distributions remained monomodal as shown by SEC (vide infra) and in total agreement with the results obtained by Loos et al. ${ }^{[10]}$

The ${ }^{1} \mathrm{H}$ NMR spectra of the diblock copolymers allowed a verification of the relative lengths of the two blocks. The shape in the high field region for the diblock is essentially identical to that of the macroinitiator, because the methylene and methine protons from the PS backbone resonate at similar chemical shifts as the tert-buyl and methylene protons of the PtBMA block, whereas the signals of the polystyrene aromatic rings arise as two broad bands around $\delta 7$ (see the example in Figure 1, bottom). Unfortunately, the signal of the methine proton geminal to chlorine atom could not be detected. Previous work has shown the identification of this resonance only for PS blocks of relatively low $\mathrm{M}_{\mathrm{n}}{ }^{[12-13]}$

\section{(c) Synthesis of the PtBMA-b-PSarms-PDVBcore Star-block copolymers}


Starting from the diblock macroinitiators described above, the star-block polymers listed in Table 2 were prepared by ATRP (arm-first approach) with divynylbenzene as cross-linking agent, still with use of $\mathrm{CuCl} / \mathrm{PMDETA}$ in toluene, at $80^{\circ} \mathrm{C}$.

Table 2. Core cross-linked nanogels synthesized in this work. ${ }^{a}$

\begin{tabular}{|c|c|c|c|c|c|c|c|c|}
\hline Diblock macroinitiator & $\begin{array}{l}\mathrm{Mn}_{\mathrm{SEC}} \\
\text { (Đ) }\end{array}$ & $\begin{array}{l}\text { Star-Block } \\
\text { Copolymer }\end{array}$ & $\begin{array}{l}\mathrm{Mn}_{\mathrm{SEC}} \\
(Đ)\end{array}$ & $(Đ)_{\text {star }}^{\mathrm{b}}$ & $\begin{array}{c}\text { Star } \\
\text { yield } / \%\end{array}$ & $\mathrm{R}_{\mathrm{g}} / \mathrm{nm}$ & $\mathrm{dn} / \mathrm{dc}_{\mathrm{star}}$ & $\mathrm{N}_{\text {arms SEC }}$ \\
\hline Ts-P $t \mathrm{BMA}_{30}-b-\mathrm{PS}_{19}-\mathrm{Cl}$ & $\begin{array}{l}6360 \\
(1.22)\end{array}$ & CCS-1 & $\begin{array}{l}106200 \\
(1.65)\end{array}$ & 1.10 & $21(64)$ & 8.6 & 0.182 & 16.7 \\
\hline Ts-Pt $\mathrm{BMA}_{46}-b-\mathrm{PS}_{135}-\mathrm{Cl}$ & $\begin{array}{l}20780 \\
(1.16)\end{array}$ & CCS-2 & $\begin{array}{l}280400 \\
(1.46)\end{array}$ & 1.11 & $22(50)$ & 20.6 & 0.142 & 13.5 \\
\hline Ts-PtBMA ${ }_{46}-b-\mathrm{PS}_{186}-\mathrm{Cl}$ & $\begin{array}{l}26140 \\
(1.10)\end{array}$ & CCS-3 & $\begin{array}{l}95020 \\
(2.57)\end{array}$ & 1.13 & $23(69)$ & 15.7 & 0.106 & 3.6 \\
\hline Ts-Pt $\mathrm{BMA}_{53}-b-\mathrm{PS}_{13}-\mathrm{Cl}$ & $\begin{array}{l}9120 \\
(1.45)\end{array}$ & $\mathrm{CCS}-4^{\mathrm{c}}$ & $\begin{array}{l}68940 \\
(2.16)\end{array}$ & 1.21 & $40(85)$ & 9.1 & 0.122 & 7.6 \\
\hline Ts-Pt $\mathrm{BMA}_{53}-b-\mathrm{PS}_{16}-\mathrm{Cl}$ & $\begin{array}{l}9340 \\
(1.42)\end{array}$ & $\mathrm{CCS}-5^{\mathrm{c}}$ & $\begin{array}{l}102900 \\
(1.60)\end{array}$ & 1.29 & $66(71)$ & 15.0 & 0.125 & 11.0 \\
\hline Ts-Pt $\mathrm{BMA}_{53}-b-\mathrm{PS}_{97}-\mathrm{Cl}$ & $\begin{array}{l}17850 \\
(1.25)\end{array}$ & CCS-6 & $\begin{array}{l}37980 \\
(1.59)\end{array}$ & 1.06 & $12(65)$ & 11.5 & 0.129 & 2.1 \\
\hline
\end{tabular}

${ }^{\mathrm{a}}$ Conditions (except for CCS-4 and CCS-5): $[\mathrm{Cu}]=[\mathrm{PMDETA}]=[\mathrm{MI}],[\mathrm{DVB}]:[$ toluene $]=1: 10$, reaction time $=24 \mathrm{~h}^{\mathrm{b}}{ }^{\mathrm{E}}$ Estimated after deconvolution of the SEC RI trace (values from the SEC MALLS trace in parentheses). ${ }^{\mathrm{c}}[\mathrm{Cu}]=[\mathrm{PMDETA}]=2 *[\mathrm{MI}]$, reaction time $=36 \mathrm{~h}$. A ratio of $[\mathrm{DVB}] /[\mathrm{MI}]=20$ was used for all the reactions.

The SEC analyses revealed that in each case the reaction was not complete, with a certain amount of linear diblock copolymer remaining present. Selected results are shown in Figure 2, in which the different evolution as followed by SEC is presented. The arm-to-star conversion, was evaluated by deconvolution of the SEC signal (see Table 2). In principle, the RI data should provide a more reliable estimation of the relative weight fractions since the MALLS response becomes smaller for lower molecular weight solutes. It is well known that an incomplete crosslinking from arm macroinitiators and difunctional monomers is obtained under typical ATRP conditions. ${ }^{[1,14-16]}$ The dispersity of the resulting cross-linked polymers were in some cases rather poor, as shown in Table 2, but the dispersity of the cross-linked fraction as estimated after deconvolution of the SEC trace was always similar to that of the precursor linear polymer. Improved results in terms of cross-linking were obtained when the amount of catalyst was doubled relative to that of macroinitiator and when the reaction time was prolonged to $36 \mathrm{~h}$, as was the case for CCS-4 and CCS-5. The shift of the molecular weigth distributions revealed the inclusion of an average number of arms per star-block copolymer as indicated in Table 2, as estimated from the ration between $\mathrm{Mn}_{\mathrm{SEC}}(\mathrm{star}-\mathrm{block})$ and $\mathrm{Mn}_{\mathrm{SEC}}(\mathrm{arms})$. This number is between 
7 and 16 for all polymers except for CCS-3 and CCS-6, for which the star-block product contained a smaller number of arms on average. The same crosslinker (DVB) / macromonomer ratio was used in all cases. The lower degree of crosslinking for these polymer may be related to the longer arm length and consequent diffusional problems, which privilege the reaction of the active radical with the smaller crosslinker molecules. However, note that CCS-2, also derived from relatively long arms, leads to a greater degree of crosslinking.

MALLS detector
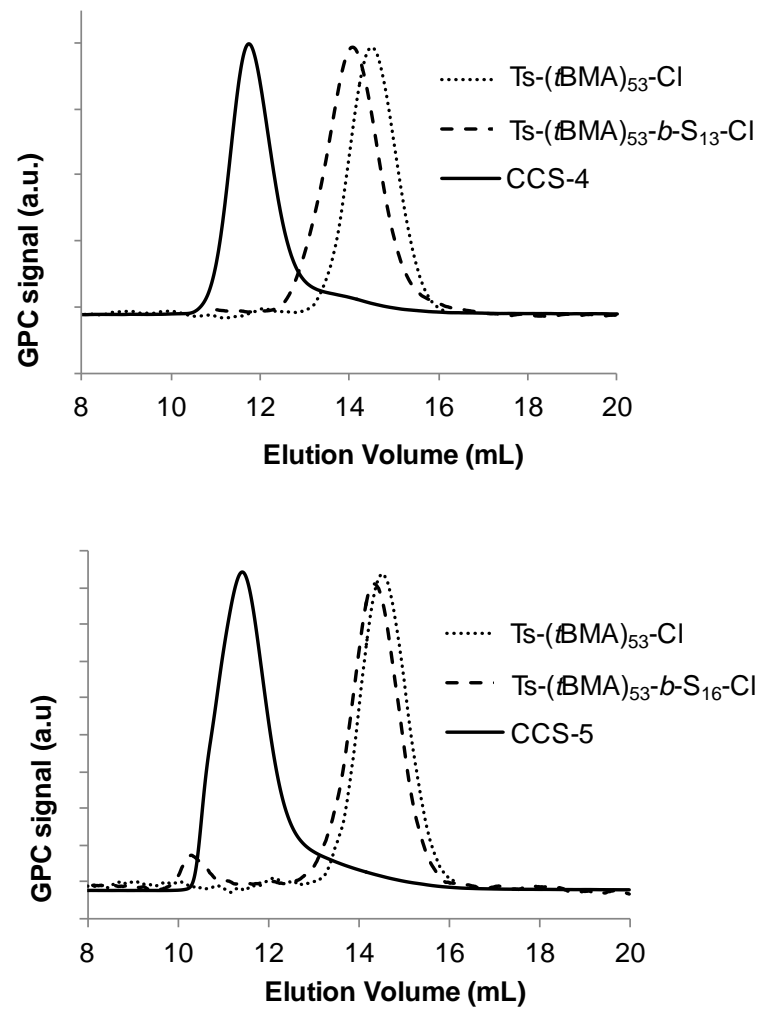

RI detector
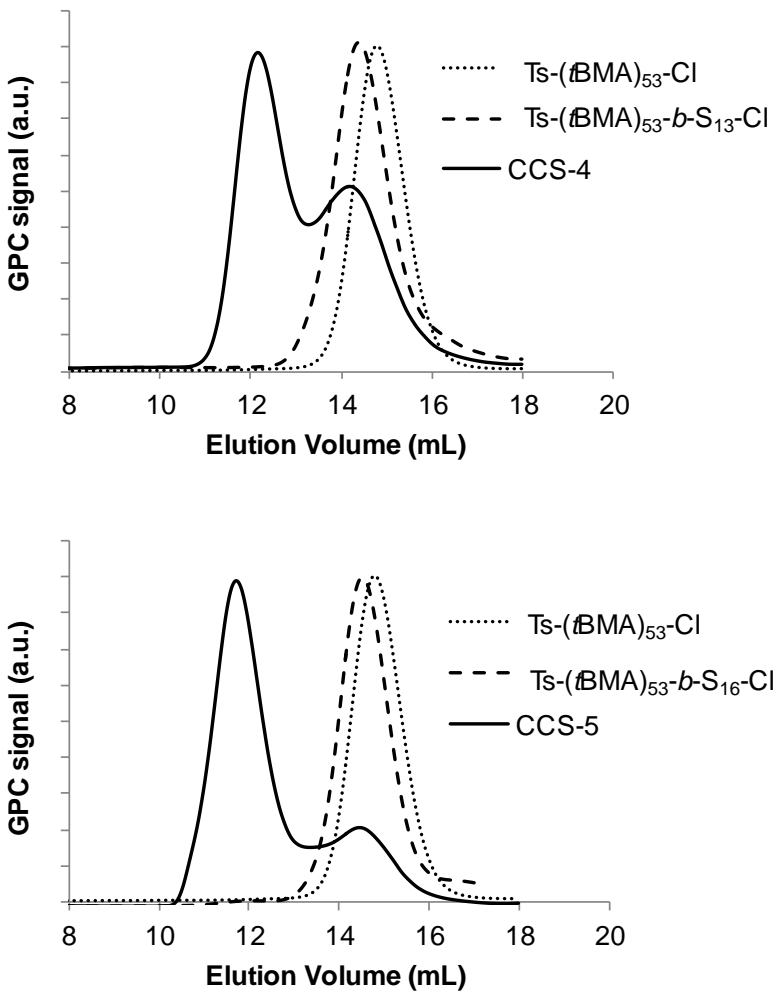

Figure 2. Size exclusion chromatograms (left: MALLS detector; right: RI detector) for selected polymers. In each frame are reported the SEC of the synthesized star-block (PtBMA- $b$-PS) arms $^{-}$ PDVB $_{\text {core }}$ copolymer (plain line) in comparison with the corresponding linear diblock (dashed line) and Ts-P $t$ BMA-Cl macroinitiator (dotted line).

The proton NMR analysis of the star-block products was not very informative, because once again the $\mathrm{Cl}$-bonded methine resonance was not detectable and the vinyl groups remaining pendant in the core of the polymer were also invisible. The signals generated by the PtBMA segments remained well defined, as it can be seen in Figure 3. 


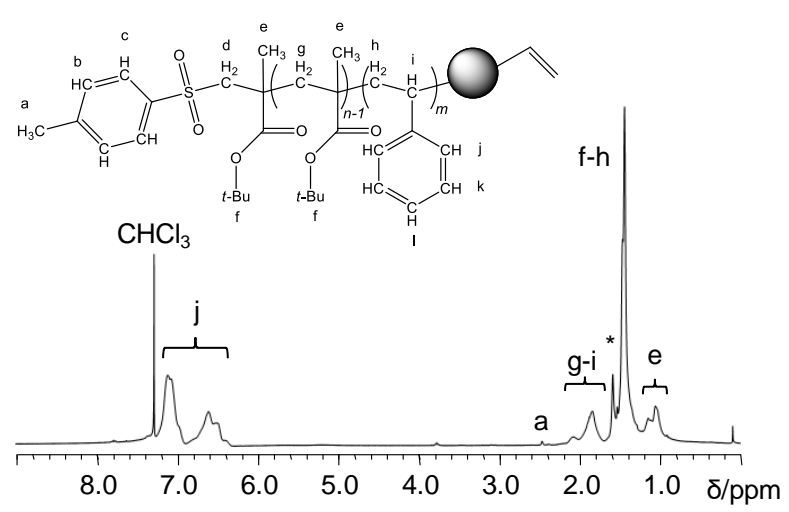

Figure 3. ${ }^{1} \mathrm{H}$ NMR spectra of CCS-3 in $\mathrm{CDCl}_{3}$. Residual solvent signals are represented by an asterisk $(*)$.

In spite of the similar resonances of both species (star-block and linear arms) on the ${ }^{1} \mathrm{H}$ NMR spectrum, their different size and molecular weight result in different diffusional behavior in solution and this can be verified by Diffusion Ordered SpectroscopY (DOSY). DOSY can discriminate and analyze separately the different species in solution since it provides a direct path to the diffusion coefficient and therefore to the hydrodynamic radius through the DebyeEinstein theory. ${ }^{[17]}$ The general case of a spherical particle yields equation 2, where $D_{A B}$ is the diffusion coefficient of the $A$ specie through a viscous medium $B, T$ the absolute temperature, $k_{B}$ the Boltzmann constant, $\eta$ is the medium viscosity and $r_{H}$ the hydrodynamic radius. The bigger the particle, the slower its movement and hence its diffusion coefficient will be smaller.

$D_{A B}=\frac{k_{B} T}{6 \pi \eta r_{H}}$

In our case, a single sample of CCS-3 was tested by adding tetramethylsilane (TMS) as an inert internal reference, to eliminate the need to know the medium viscosity (equation 3 ). ${ }^{[18]}$ The resulting 2-D spectrum is shown in Figure 4. The ${ }^{1} \mathrm{H}$ NMR data were processed using NMR notebook software with a DOSY module from NMRTEC® that implements the Maximum Entropy / Laplace Inversion Transform algorithm. ${ }^{[19]}$ This complement is well adapted for the treatment of polydisperse samples. ${ }^{[20]}$ 


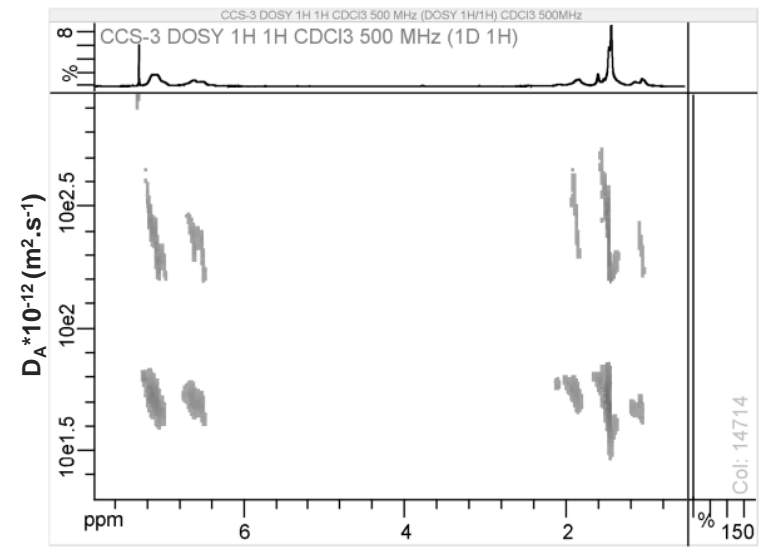

Figure 4. NMR DOSY spectrum for CCS-3 at $298 \mathrm{~K}$ in $\mathrm{CDCl}_{3}$.

As expected, the analysis yielded two major species other than TMS, i.e. the star-block cross-linked polymer and the residual diblock macroinitiator. The DOSY method should provide a better analysis of the relative fractions and yield of the cross-linking reaction than the SEC since the response of the latter depends on the quality of the separation. This is true if the species have a relatively narrow molecular weight distribution and no perturbations to the Brownian movement are present such as convection or settling. Their relative proportions as integrated from the signal intensity in the DOSY differed from those resulting from the deconvolution of the SEC data (see Table 3). Note that the analyzed sample yields a crosslinking yield from the DOSY data that agrees better with the MALLS signal deconvolution than with that of the RI signal. The size of the star-block particle as estimated by the hydrodynamic radius is also in good agreement with the gyration radius determined from the analysis of three-angle light scattering data at the maximum of the SEC peak (Table 2).

$$
\frac{D_{A}}{D_{T M S}}=\frac{r_{H}^{T M S}}{r_{H}{ }^{A}}
$$

Table 3. Average diffusion coefficients of the species contained in sample CCS-3 in $\mathrm{CDCl}_{3}$ at $298 \mathrm{~K}$.

\begin{tabular}{|l|c|c|c|}
\hline Species & $D_{A}\left(\mathrm{~m}^{2} \cdot \mathrm{s}^{-1}\right)$ & $r_{H}(\mathrm{~nm})$ & Relative amount $^{\mathrm{a}}(\%)$ \\
\hline TMS & $1.66 \cdot 10^{-9}$ & $0.49^{\mathrm{b}}$ & - \\
\hline Linear diblock $^{\mathrm{c}}$ & $2.50 \cdot 10^{-10}$ & 6.3 & 36 \\
\hline Star-block & $5.30 \cdot 10^{-11}$ & 14.1 & 64 \\
\hline
\end{tabular}

${ }^{\mathrm{a}}$ From the intensity integral. ${ }^{\mathrm{b}}$ Calculated assuming a tetrahedral geometry and bond lengths for $(\mathrm{C}-\mathrm{H})=109 \mathrm{pm}$ and $(\mathrm{Si}-\mathrm{C})=185 \mathrm{pm} .{ }^{\mathrm{c}}$ Residual Ts-PtBMA $46-b-\mathrm{PS}_{186}-\mathrm{Cl}$. 


\section{(d) Acrylate system}

Following the same strategy described previously in (a)-(c), an acrylate analogue, (PtBA$b$-PS $)_{\text {arms }}-\mathrm{PDVB}_{\text {core, }}$ was also synthesized. Only one star-block copolymer was prepared with the purpose of comparing the solubility behavior as a function of the outer shell structure. First, a $\mathrm{P} t \mathrm{BA}-\mathrm{Br}$ macroinitiator was prepared using methyl-2-bromopropionate (MBP) as initiator and $\mathrm{CuBr} / \mathrm{PMDETA}$ as catalyst, which is more suitable for acrylate monomers using conditions found in the literature. ${ }^{[21-23]}$ The same kind of diblock copolymers have also been previously obtained under slightly different conditions. ${ }^{[24]}$ The SEC and ${ }^{1} \mathrm{H}$ NMR analyses yielded an average formulation of $\mathrm{CH}_{3} \mathrm{CH}(\mathrm{COOMe})-\mathrm{P} t \mathrm{BMA} 40-\mathrm{Br}\left(\mathrm{Mn}_{\mathrm{SEC}}=5310 ; \mathrm{Ð}=1.15\right)$. This macroinitiator was subsequently chain extended with styrene and cross-linked under the same conditions described above for the Ts-PtBMA-Cl macroinitiator. The intermediate diblock macroinitiator corresponds to $\mathrm{CH}_{3} \mathrm{CH}(\mathrm{COOMe})-\mathrm{P}_{t} \mathrm{BMA}_{40}-b-\mathrm{PS}_{31}-\mathrm{Br}\left(\mathrm{Mn}_{\mathrm{SEC}}=8620 ; \mathrm{Ð}=1.30\right)$ according to the SEC and ${ }^{1} \mathrm{H}$ NMR analyses. Similar block copolymers have also been previously prepared by the reverse order monomer addition (first styrene, then $t \mathrm{BA}$ ), yielding diblock macroinitiators with the halogen attached to the PtBA end and with a similar level of control. ${ }^{[25]}$ The final (PtBA- $b$-PS) arms-PDVB ${ }_{\text {core }}$ star-block polymer obtained by cross-linking the $\mathrm{CH}_{3} \mathrm{CH}(\mathrm{COOMe})-\mathrm{P} t \mathrm{BMA}_{40}-b-\mathrm{PS}_{31}-\mathrm{Br}$ macroinitiator had $\mathrm{Mn}_{\mathrm{SEC}}=213100$ and $\mathrm{Ð}=1.42$, from which an average of 24 arms can be calculated.

\section{(e) Hydrolysis. Generation of amphiphilic star-block copolymers.}

The amphiphilic character of final polymers is conferred by the final hydrolysis step. Single PAA and PMAA polymers prepared by ATRP, as well as block copolymers containing these segments, have already been prepared by tert-butyl ester segment hydrolysis. ${ }^{[21,24,26]}$ Both linear and star-like copolymers were hydrolyzed under moderate acid conditions in order to achieve an effective water solubilisation (see Scheme 2).

Both PAA and PMAA homopolymers are intrinsically water soluble, but their copolymers with styrene are not, although they can be solubilised in micellar form depending on the relative size of the two blocks. ${ }^{[24,26-29]}$ A good solvent for both blocks is DMSO and this has indeed been used, in the deuterated version, for the ${ }^{1} \mathrm{H}$ NMR study of the hydrolyzed copolymers. 


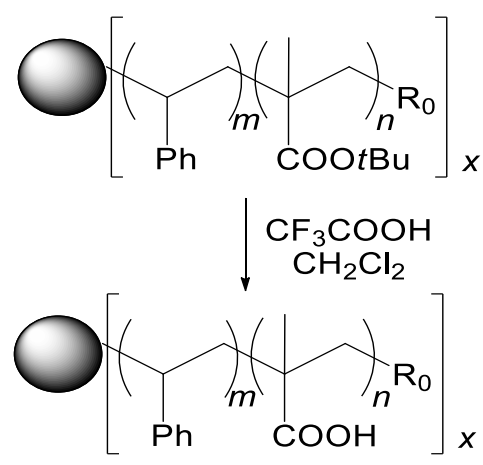

PMAA outer block
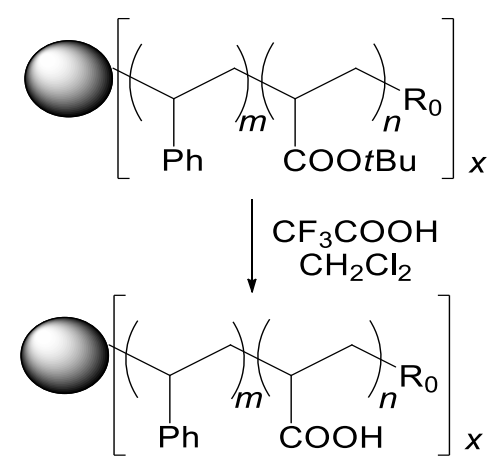

PAA outer block

Scheme 2. Hydrolysis sequence on tert-butyl groups and synthesis of the poly(acid) external segments.

The completion of the hydrolysis step was checked by ${ }^{1} \mathrm{H}$ NMR spectrometry. The $t \mathrm{Bu}$ resonance at $\delta=1.45 \mathrm{ppm}$ disappears from the spectrum and is replaced by a broad band for the carboxylic acid functions. As an example, the ${ }^{1} \mathrm{H}-\mathrm{NMR}$ spectra of the Ts-P $t \mathrm{BMA}_{46}-b-\mathrm{PS}_{186}-\mathrm{Cl}$ linear arms before (a) and after hydrolysis (b) are represented in Figure 5.

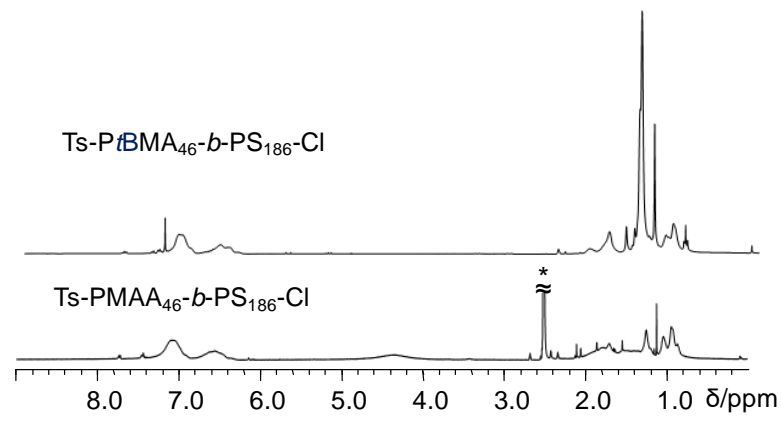

Figure 5. ${ }^{1} \mathrm{H}$ NMR spectra of Ts-P $t \mathrm{BMA}_{46}-b-\mathrm{PS}_{186}-\mathrm{Cl}$ in $\mathrm{CDCl}_{3}$ (top) and Ts-PMAA $46-b$ - $\mathrm{PS}_{186}-$ $\mathrm{Cl}$ in $\left(\mathrm{CD}_{3}\right)_{2} \mathrm{SO}$ (bottom). The starred resonance is the DMSO solvent peak.

The linear copolymers and the star-block copolymers obtained were not directly soluble in water in the acidic form, most certainly because of the unfavorable contribution of hydrophobic polystyrenic chains. However, they could be dissolved at basic $\mathrm{pH}$ with $\mathrm{K}_{2} \mathrm{CO}_{3}$ upon heating under vigorous stirring in order to obtain homogeneous polyelectrolyte solutions (see Scheme $3)^{22}$ The potassium salt form of the linear block copolymers will be named as PMAAK $\mathrm{n}-b-\mathrm{PS}_{\mathrm{m}}$ or PAAK $\mathrm{K}_{\mathrm{n}}-b-\mathrm{PS}_{\mathrm{m}}$, with $n$ and $m$ corresponding respectively to the number of methacrylic/acrylic units and styrene units.
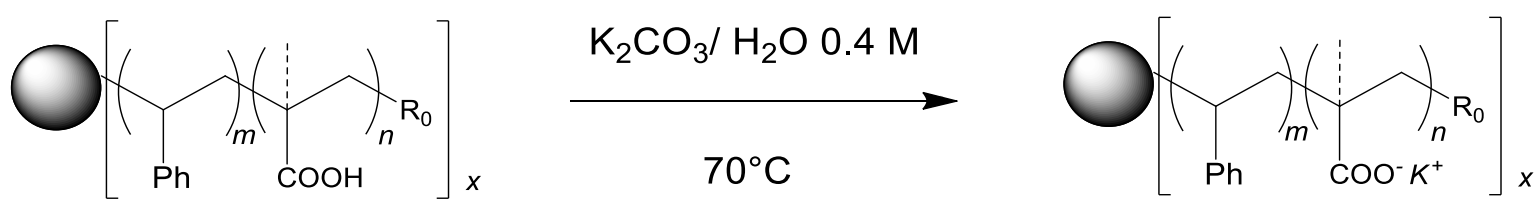
Scheme 3. General procedure of acid units' neutralization, for a methacrylate system.

The results of the solubilization tests are shown in Table 4. Both PMAA $46-\mathrm{Cl}$ and $\mathrm{PAA}_{40-}$ $\mathrm{Br}$ homopolymers were water-soluble. Clear and colorless solutions were obtained when using the linear and star-block copolymers containing the acrylic block. For polymers containing both methacrylate and styrene segments, a milky-white dispersion was observed, as already reported in previous contributions. ${ }^{[30]}$ Since the size of these linear diblock and start-block copolymers should not exceed a few tens of nanometers (e.g. $28 \mathrm{~nm}$ diameters for CCS-3, see above), the light scattering observed for these polymer solutions must be due to aggregation, probably caused by an incomplete ionization and the consequent establishment of inter-macromolecule $\mathrm{H}$ bonds. Indeed, it is known that the pKa of PMAA is ca. 6.5 for the first acid dissociation but increases rapidly for the subsequent dissociations up to $>9 .{ }^{[31]}$ The first $\mathrm{pK}_{\mathrm{a}}$ of PAA, on the other hand, is $<4$ and increases for subsequent dissociations up to ca. 7. The establishment of intermicellar interactions, affecting the light scattering of aqueous solutions of PS- $b$-PMAA micelles, has previously been investigated in detail. ${ }^{[32]}$

Table 4. Water solubility features of polymers and corresponding white solutions.

\begin{tabular}{|c|c|c|c|}
\hline Hydrolyzed Polymer & Resulting Polymer & $\mathrm{N}^{\circ}$ of acid units & $\begin{array}{c}\text { solution } \\
\text { appearance }\end{array}$ \\
\hline $\mathrm{Ts}-\mathrm{PMAA}_{30}-\mathrm{PS}_{19}-\mathrm{Cl}$ & Ts-PMAAK $_{30}-\mathrm{PS}_{19}-\mathrm{Cl}$ & 30 & White \\
\hline Ts-PMAA $_{46}-\mathrm{PS}_{135}-\mathrm{Cl}$ & $\mathrm{Ts}_{-} \mathrm{PMAAK}_{46}-\mathrm{PS}_{135}-\mathrm{Cl}$ & 46 & White \\
\hline $\mathrm{Ts}-\mathrm{PMAA}_{53}-\mathrm{PS}_{97}-\mathrm{Cl}$ & Ts-PMAAK $_{53}-\mathrm{PS}_{97}-\mathrm{Cl}$ & 53 & White \\
\hline CCS-1 & $\left(\mathrm{Ts}-\mathrm{PMAAK}{ }_{30}-\mathrm{PS}_{19}\right)_{16.7} \mathrm{PDVB}$ & 30 & White \\
\hline CCS-2 & $\left(\mathrm{Ts}-\mathrm{PMAAK}{ }_{46}-\mathrm{PS}_{135}\right)_{13.5} \mathrm{PDVB}$ & 46 & White \\
\hline CCS-6 & $\left(\mathrm{Ts}_{\mathrm{S}} \mathrm{PMAAK}{ }_{53}-\mathrm{PS}_{97}\right)_{2.1} \mathrm{PDVB}$ & 53 & White \\
\hline Ts-PMAA $46-\mathrm{Cl}$ & - & 46 & Clear \\
\hline $\begin{array}{c}\mathrm{CH}_{3} \mathrm{CH}(\mathrm{COOMe})- \\
\mathrm{PAA}_{40}-\mathrm{Br}\end{array}$ & - & 40 & Clear \\
\hline $\begin{array}{c}\mathrm{CH}_{3} \mathrm{CH}(\mathrm{COOMe})- \\
\mathrm{P}_{t} \mathrm{BA}_{40}-\mathrm{PS}_{31}-\mathrm{Br}\end{array}$ & $\mathrm{CH}_{3} \mathrm{CH}(\mathrm{COOMe})-\mathrm{PAAK}_{40}-\mathrm{PS}_{31}-\mathrm{Br}$ & 40 & Clear \\
\hline CCS-7 & $\begin{array}{c}\left(\mathrm{CH}_{3} \mathrm{CH}(\mathrm{COOMe})-\mathrm{PAAK}_{40^{-}}\right. \\
\left.\mathrm{PS}_{31}\right)_{24} \mathrm{PDVB}\end{array}$ & 40 & Clear \\
\hline
\end{tabular}

\section{(f) Atomic Force Microscopy (AFM) characterization}

AFM analyses were performed in tapping mode on some of the synthesized linear diblock and star-block copolymers. Figure 6 shows an example of AFM topographical and phase demodulation images for the star polymer CCS-2 (C and D, respectively), and for its linear 
diblock copolymer precursor Ts- $t_{\mathrm{BMA}} \mathrm{B}_{46}-b-\mathrm{PS}_{135}-\mathrm{Cl}$ (A and $\mathrm{B}$, respectively). Images $\mathrm{A}$ and $\mathrm{B}$ display the characteristic periodic pattern typical of a block copolymer, ${ }^{[33]}$ well seen with both topographic and demodulation imaging. However, the size of the "bright" objects is in our case around 500 x $800 \mathrm{~nm}$, much larger than for segregated phases seen by AFM with classical styrene-rubber block copolymers. ${ }^{[34]}$ Also the optical contrast in demodulation images is softer, but this can be due to the fact that in our case the two polymeric blocks, although phasesegregated, show similar rigidity having in both cases a $\mathrm{T}_{\mathrm{g}}$ close to $+100^{\circ} \mathrm{C}$. Actually the DSC curve of Ts-P $t \mathrm{BMA}_{46}-b-\mathrm{PS}_{135}-\mathrm{Cl}$ sample shows two glass transitions at 94 and $113{ }^{\circ} \mathrm{C}$ in the first heating run (Figure 7) and the presence of two $\mathrm{T}_{\mathrm{g}}$ temperature confirms the phase separation and morphology shown in images A and B. Nevertheless, only one glass transition at $116{ }^{\circ} \mathrm{C}$ appears in third heating run (Figure 7), because the phase segregation of the relatively low molecular weight blocks seems to be unstable at increasing temperature. Qualitatively, a similar behavior was also observed for the CCS-2 sample. The AFM images of the crosslinked samples show a higher surface roughness (the $\mathrm{R}_{\mathrm{rms}}$ passes from $1.25 \pm 0.2$ to $3.43 \pm 0.5 \mathrm{~nm}$ ), likely because the chemical crosslinking worsens the film forming properties. Rounded objects are observed for CCS-2 in Figure 6 (image C), and the phase image lacks contrast suggesting a more homogeneous composition of the nanogel outer shell.
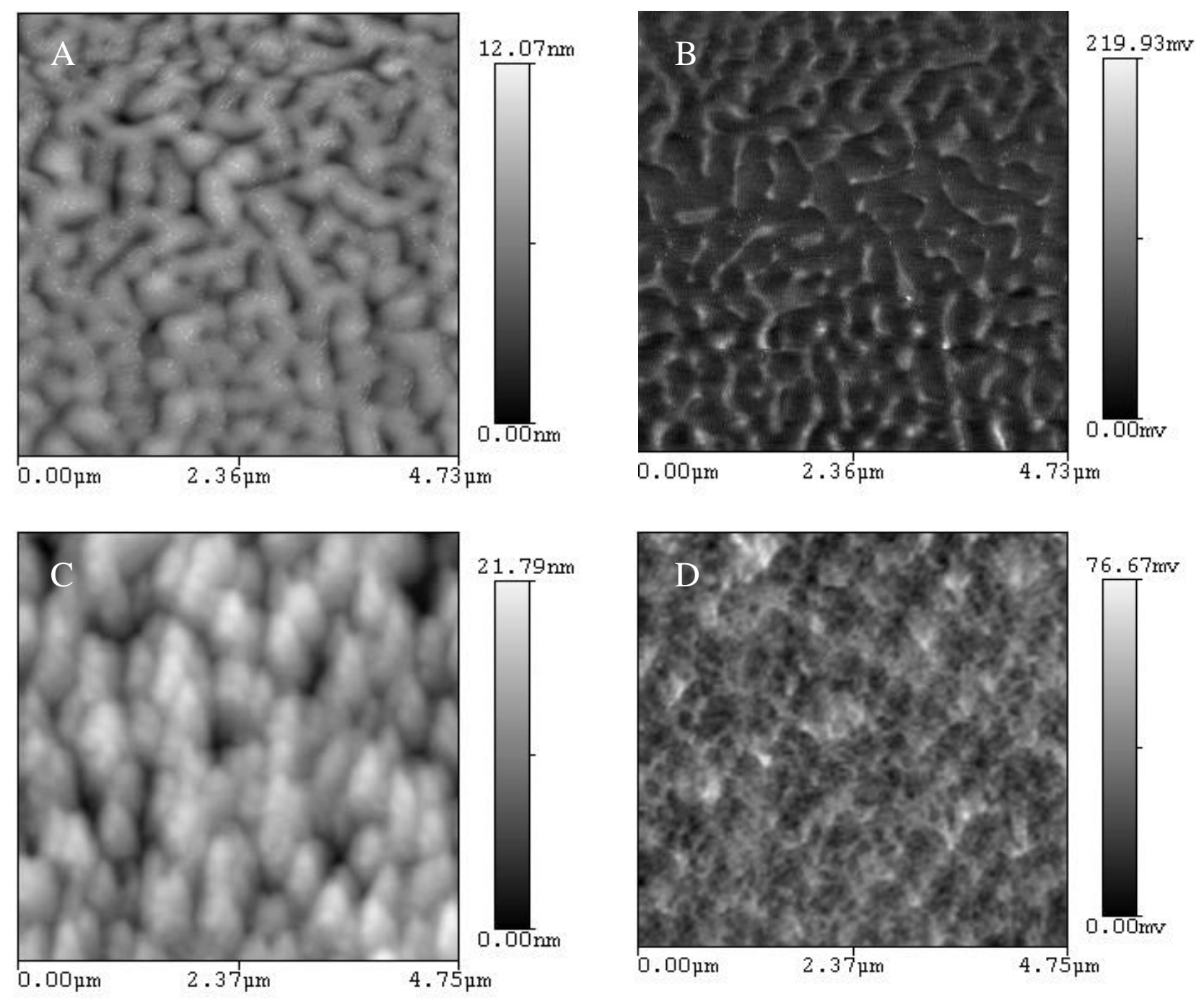
Figure 6. Topographical (A - C) and phase demodulation (B - D) images, respectively for Ts$\mathrm{P} \mathrm{BMA}_{46}-b-\mathrm{PS}_{135}-\mathrm{Cl}$ and CCS-2 samples dispersed in acetone and spin-coated (scanning area $5 \mathrm{x}$ $\left.5 \mu \mathrm{m}^{2}\right)$.

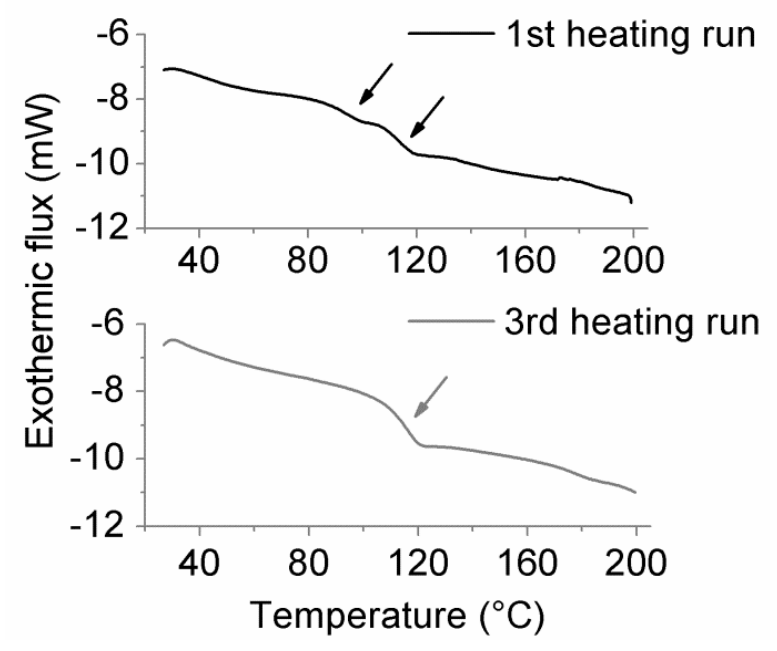

Figure 7. DSC traces of TsP $t \mathrm{BMA}_{46}-b-\mathrm{PS}_{135}-\mathrm{Cl}$ sample obtained in the first heating run (black line) and in the third heating run (gray line). The arrows indicate the inflection points of curves, corresponding to the glass transition temperatures.

Figure 8 shows the topographical images for the CCS-2 and CCS-3 samples cast from acetone solutions, performed in tapping mode on a scanning area of $1.35 \times 1.35 \mu \mathrm{m}$. From the corresponding topographical data it is possible to recognize ellipsoidal objects with widths in the range of $250-500 \mathrm{~nm}$ and heights of $10-15 \mathrm{~nm}$. The lateral size of these structures is significantly larger than hydrodynamic radii of nanogels as measured by NMR data (see Table 3). Such a discrepancy can be due to a partial coalescence of nanogels during the coating and drying process, so that only aggregates are seen by AFM analysis.
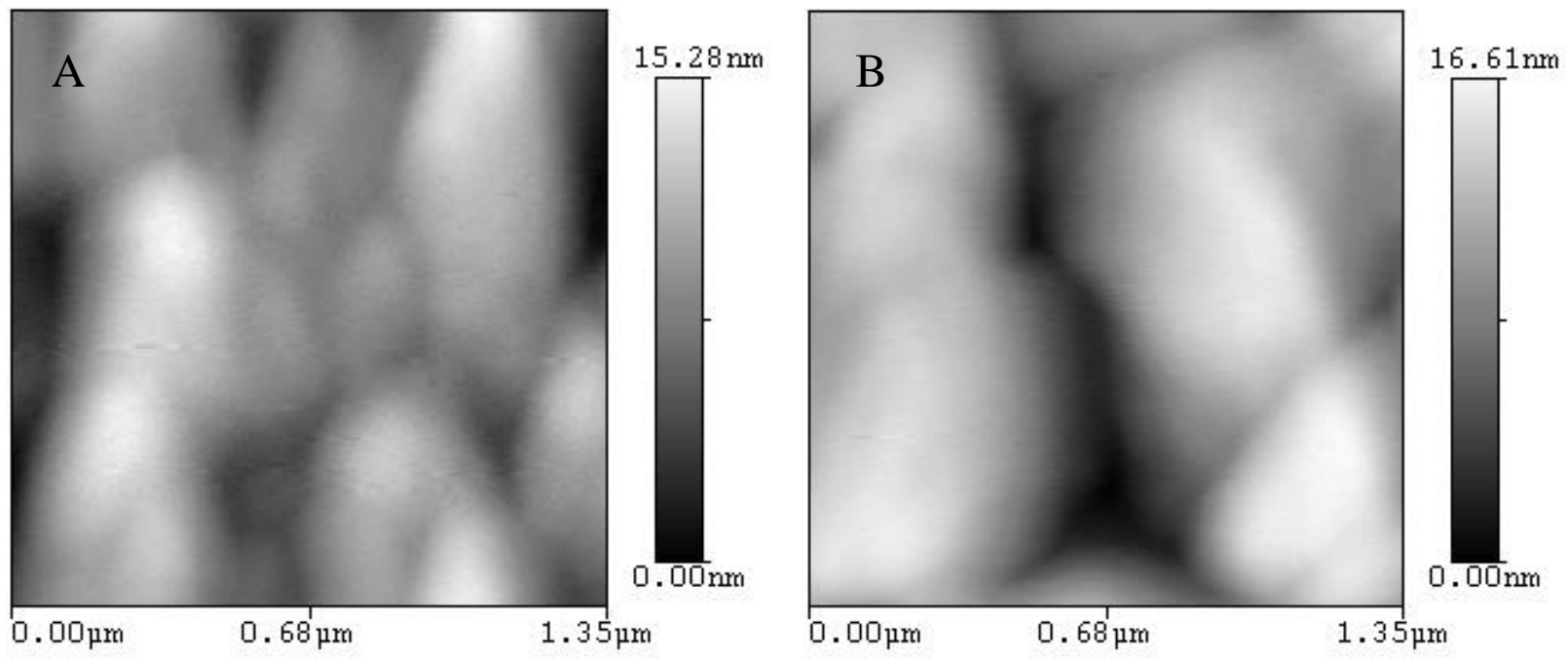
Figure 8. Three-dimensional topographical image for the CCS-2 (A) and CCS-3 (B) samples dispersed in acetone and spin-coated (scanning area $10 \times 10 \mu \mathrm{m}^{2}$ ).

Figure 9 highlights the effect of the solvent on the apparent particle size: in comparison to the morphology obtained from acetone casting (Figure 8B), CCS-3 sample cast from dichloromethane or toluene solutions shows much smaller structures, about 100-150 nm and 50$100 \mathrm{~nm}$ wide, respectively. These dimensions are still large but in better agreement with the NMR data.
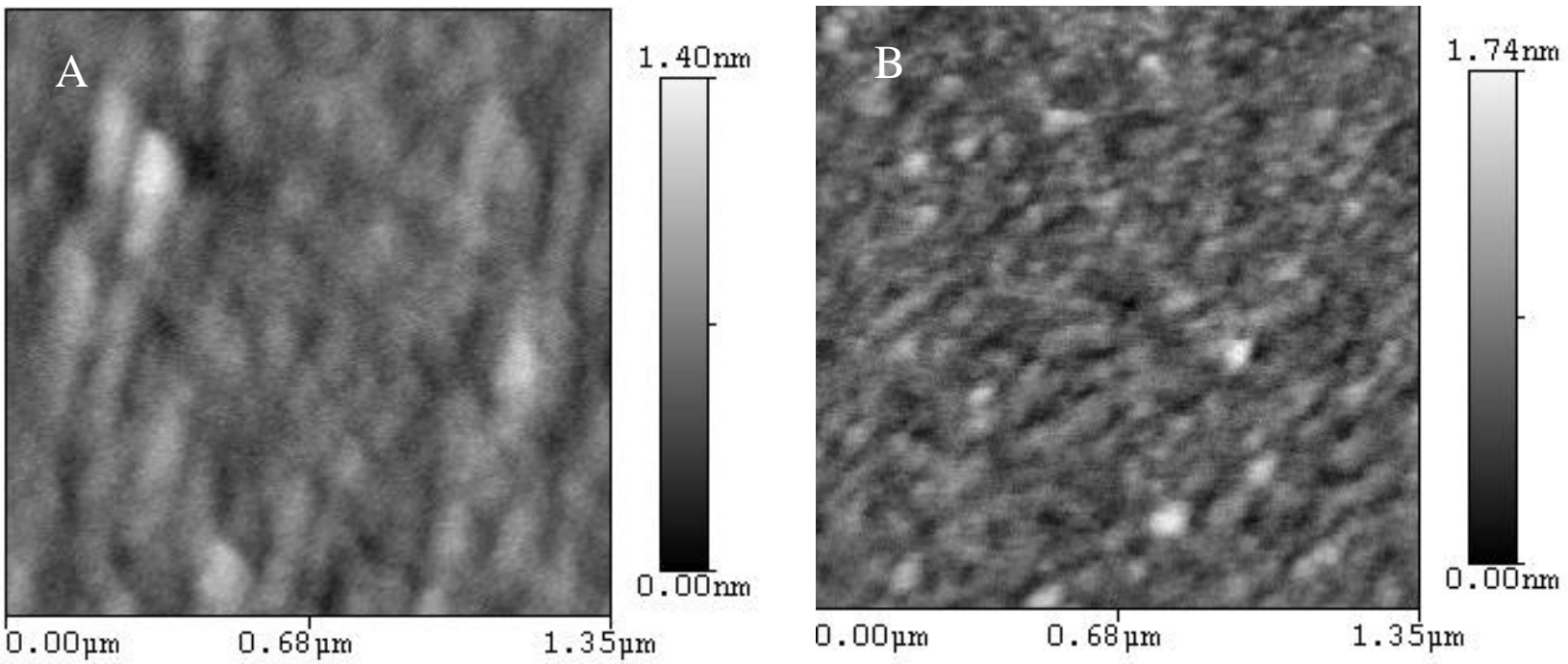

Figure 9. AFM topographical images for CCS-3 samples dispersed in (A) dichloromethane and in (B) toluene and spin-coated on silicon (scanning area $1.35 \times 1.35 \mu \mathrm{m}^{2}$ ).

Such an effect may be related to the different features of the solvents used. Table 5 reports the solubility parameter components ${ }^{[35]}$ of the three solvents in comparison to polystyrene, which is the predominant species of the block copolymers described in the present work. From the examination of Table 5 data it seems that both dichloromethane and toluene show higher dispersive $\delta_{\mathrm{d}}$ and smaller polar $\delta_{\mathrm{p}}$ components, with values closer to those of polystyrene. Smaller differences between polymer-solvent solubility parameter components involve a better thermodynamic quality of the solutions, and a more efficient solubilization of the nanogels in our case. On the other hand acetone is expected to be a poorer solvent, and formation of larger size colloidal aggregates is likely. In the light of the above the smaller objects seen after dichloromethane or toluene casting seems a more realistic evaluation of the size of the single particle nanogels. 
Table 5. Three-component solubility parameters (dispersion, $\delta_{\mathrm{d}}$, polar, $\delta_{\mathrm{p}}$, and hydrogen bonding components, $\delta_{\mathrm{h}}$ ) for polystyrene and solvents. ${ }^{[35]}$

\begin{tabular}{|l|c|c|c|}
\hline & $\delta_{\mathrm{d}}\left(\mathrm{MPa}^{1 / 2}\right)$ & $\delta_{\mathrm{p}}\left(\mathrm{MPa}^{1 / 2}\right)$ & $\delta_{\mathrm{h}}\left(\mathrm{MPa}^{1 / 2}\right)$ \\
\hline Polystyrene & 21.3 & 5.8 & 4.3 \\
\hline Acetone & 15.5 & 10.4 & 7.0 \\
\hline Dichloromethane & 18.2 & 6.3 & 6.1 \\
\hline Toluene & 18.0 & 1.4 & 2.1 \\
\hline
\end{tabular}

\section{Conclusions}

Using the precision of the ATRP technique, core-crosslinked core-shell nanosized polymers with flexible PS- $b$-P $t$ BMA or PS- $b$-P $t$ BA arms were prepared in three steps. The outer poly(tert-butyl (meth)acrylate) shell was then hydrolyzed to PMAA or PAA to afford amphilic core-shell structures that could be dissolved in water in the deprotonated form. The star-block polymer containing an outer PAA shell is more easily soluble in water, without aggregation, to yield clear solutions. The synthesis suffers from incomplete crosslinking, leaving a significant fraction of arms, which is a frequently encountered limitation for these convergent methods of synthesis. ${ }^{[1,6]}$ However, methods allowing improved crosslinking efficiency exist. ${ }^{[14-15,36]}$ Future synthetic efforts in our group will be devoted to the construction of this type of polymer architecture with a PAA outer shell, with a functionalized hydrophobic core, for specialized applications. As mentioned in the introduction, the PAA shell should insure confinement of the polymer in the water phase for a variety of water/organic biphasic systems, for instance water/toluene, even at relatively high temperatures. The investigation of the phase distribution as a function of temperature and relative size of the core and shell parts is one of the objectives of our future studies.

\section{Experimental Part}

Chemicals. All monomers (styrene, 99\%; tert-butyl methacrylate, 98\%; tert-butyl acrylate, 98\%; divinylbenzene, tech. $80 \%$ ) were purchased from Aldrich, distilled under reduced pressure from $\mathrm{CaH}_{2}$ and stored under argon at $-20^{\circ} \mathrm{C}$ before use. Toluene $(99.7 \%$, Aldrich) was dryed and distilled under argon. $\mathrm{CuBr}$ (99.999\%, Aldrich), $\mathrm{CuCl}$ (99.999\%, Aldrich), $\mathrm{CuBr}_{2}$ (99.0\%, Fluka), p-tosyl chloride (99.0\%, Fluka), methyl 2-bromopropionate (99.0\%, Fluka) PMDETA (99\%, 
Aldrich), methanol (99.8\%, Aldrich) and THF (99.9\%, Aldrich) were used without further purification.

Instrumentation. The ${ }^{1} \mathrm{H}$ NMR spectra were recorded on Bruker ARX250 or Avance 300 spectrometers in $\mathrm{CDCl}_{3}$ for all the hydrophobic precursor polymers and in DMSO- $d_{6}$ for the hydrolyzed amphiphilic polymers. The NMR DOSY analysis of CCS-3 was carried out at $298 \mathrm{~K}$ on a Bruker $500 \mathrm{MHz}$ spectrometer in $\mathrm{CDCl}_{3}$ solutions. The experiments were performed using a stimulated echo bipolar gradiant for diffusion sequence. For each experiment, fine-shaped pulsed-field gradients with a duration of $1.4 \mathrm{~ms}$ followed by a recovery delay of $150 \mu$ s were used. The diffusion space was recorded by 32 linearly spaced gradients with a diffusion time of 220 ms. Diffusion coefficients were obtained by treatment of the NMR data with NMR notebook software which included the Maximum Entropy/Inverse Laplace Transformation algorithm developed by NMRTEC®. The size exclusion chromatographic analyses (SEC) were carried out in filtered THF as eluent on PL gel $(5 \mu \mathrm{m}$ particles, $50 \times 7.5 \mathrm{~mm})$ guard column and a PL-gel 5 $\mu \mathrm{m}$ mixed-D (300 x $7.5 \mathrm{~mm})$ column (Polymer Laboratories), equipped with a multiangle lightscattering detector (minidawn Tristar, Wyatt Technology Corporation) coupled with a refractive index detector (RI2000, Sopares) at $35{ }^{\circ} \mathrm{C}$. Molecular weight values for the copolymers and nanogels were determined using the multiangle laser light scattering detector. For the block copolymers, the molecular weight analyses were carried out using the total mass recovery protocol, which also yields the $\mathrm{dn} / \mathrm{dc}$ value, whereas literature values of $\mathrm{dn} / \mathrm{dc}$ were used for the homopolymers (0.075 for PtBMA; 0.059 for $\mathrm{P} t \mathrm{BA})$. Gas chromatography analyses were performed on a Hewlett Packard 5980 Series II gas chromatograph equipped with a Beta DEXTM 225 capillary column and a flame ionization detector using helium as carrier gas. Differential scanning calorimetry (DSC) was performed on a Mettler-Toledo TA $823^{\mathrm{e}}$ instrument under nitrogen flux in cooling/heating runs at first from $20{ }^{\circ} \mathrm{C}$ to $200{ }^{\circ} \mathrm{C}$, then from $200^{\circ} \mathrm{C}$ to $20{ }^{\circ} \mathrm{C}$, finally from $20{ }^{\circ} \mathrm{C}$ to $200{ }^{\circ} \mathrm{C}$ at a rate of $20{ }^{\circ} \mathrm{C} \mathrm{min}-1$. The glass transition temperature (Tg) was measured at the inflection point of the first and the third heating run.

\section{Polymerizations. 1. Methacrylate systems.}

(a) Synthesis of the Ts-PtBMA46-Cl macroinitiator. By operating under an atmosphere of argon, in a dry round bottom Schlenk flask equipped with a stirrer bar were introduced $\mathrm{CuCl}$ (471.3 mg, $4.6 \mathrm{mmol})$ PMDETA $(960 \mu \mathrm{L}, 4.6 \mathrm{mmol})$, dry toluene $(10 \mathrm{~mL})$ and dodecane (as GC internal standard). The mixture was stirred for $20 \mathrm{~min}$ at room temperature before the addition of $t$ BMA (23 mL, $138 \mathrm{mmol}$ ). Finally, a separately prepared solution of the initiator (TsCl, 907.9 $\mathrm{mg}, 4.6 \mathrm{mmol}$ in $10 \mathrm{~mL}$ of toluene) was transferred into the reaction mixture. After three freezepump-thaw cycles, the flask was placed in a preheated and thermally regulated oil bath at $80^{\circ} \mathrm{C}$. 
During the reaction, several samples ( $1 \mathrm{~mL}$ of solution) were withdrawn and dissolved in $3 \mathrm{~mL}$ of toluene, followed by filtration through a small alumina column in order to remove the catalyst. One part of the colorless samples was analyzed by gas chromatography to determine the monomer conversion and the remaining part was used for the SEC analysis. After 4 hours, the Schlenk flask was rapidly cooled down and the mixture was diluted with toluene and filtered through an alumina column. The resulting solution was concentrated by evaporation under reduced pressure and the polymer was precipitated by addition of $\mathrm{MeOH}$, filtered off and dried overnight under vacuum to yield a white powder. Yield $16 \mathrm{~g}(76 \%) . \mathrm{Mn}_{\mathrm{SEC}}=6730 \mathrm{~g} / \mathrm{mol} ; \mathrm{Ð}=$ 1.10 .

(b) Synthesis of the other Ts-PtBMAn-Cl macroinitiators. The procedure was identical to that described in the previous section, except for the use of $\mathrm{CuBr}$ and different monomer quantities, as follows:

Ts-PtBMA $30-\mathrm{Cl}: \mathrm{CuBr}(197.6 \mathrm{mg}, 1.35 \mathrm{mmol}), \mathrm{CuBr}_{2}(33.5 \mathrm{mg}, 0.15 \mathrm{mmol})$, PMDETA (323 $\mu \mathrm{L}$, $1.5 \mathrm{mmol}), \mathrm{TsCl}(292 \mathrm{mg}, 1.5 \mathrm{mmol}), t \mathrm{BMA}(25 \mathrm{~mL}, 150 \mathrm{mmol})$, toluene $(25 \mathrm{~mL}) . \mathrm{Mn}_{\mathrm{SEC}}=$ $4380 \mathrm{~g} / \mathrm{mol} ; \mathrm{Ð}=1.05$.

Ts-PtBMA53-Cl: CuBr (197.6 mg, 1.35 mmol), CuBr 2 (33.5 mg, 0.15 mmol), PMDETA (323 $\mu \mathrm{L}$, $1.5 \mathrm{mmol}), \mathrm{TsCl}(292 \mathrm{mg}, 1.5 \mathrm{mmol}), t \mathrm{BMA}(45 \mathrm{~mL}, 270 \mathrm{mmol})$, toluene $(45 \mathrm{~mL}) . \mathrm{Mn}_{\mathrm{SEC}}=$ $7730 \mathrm{~g} / \mathrm{mol} ; Ð=1.03$.

(c) Synthesis of Ts-PtBMA-b-PS-Cl. The procedure was similar to that discussed in the previous section. Only the synthesis of Ts- $t \mathrm{BMA}_{46}-b-\mathrm{S}_{135}-\mathrm{Cl}$ will be described in detail. To the solution of copper catalyst $(\mathrm{CuCl}, 71.5 \mathrm{mg}, 0.7 \mathrm{mmol})$ and PMDETA $(150 \mu \mathrm{L}, 0.7 \mathrm{mmol})$ in toluene $(6 \mathrm{~mL})$, the monomer (styrene, $5 \mathrm{~mL}, 42 \mathrm{mmol})$ and a solution of Ts-P $t \mathrm{BMA}_{46}-\mathrm{Cl}(4.7 \mathrm{~g}$, $0.7 \mathrm{mmol}$ in $6 \mathrm{~mL}$ of dry toluene) were added. After three freeze-pump-thaw cycles, the Schlenk flask was immersed in a preheated thermostated oil bath at $100^{\circ} \mathrm{C}$. After 7 hours, the flask was rapidly cooled down to room temperature and the reaction mixture was diluted in $30 \mathrm{~mL}$ of toluene and passed several times through an alumina column to remove the residual catalyst. It was then concentrated and the polymer was precipitated by adding cold methanol. The recovered white solid powder was dried overnight under vacuum at room temperature. Yield: $7.4 \mathrm{~g}(60 \%)$. $\mathrm{M}_{\mathrm{n}}=20780 \mathrm{~g} / \mathrm{mol}(\mathrm{dn} / \mathrm{dc}=0.141) ; Đ=1.16$.

Data for the other isolated samples:

Ts-P $t \mathrm{BMA}_{30}-b-\mathrm{PS}_{19}-\mathrm{Cl} . \mathrm{M}_{\mathrm{n}}=6360 \mathrm{~g} / \mathrm{mol}(\mathrm{dn} / \mathrm{dc}=0.106) ; \mathrm{Ð}=1.22$.

Ts-PtBMA $46-b-\mathrm{PS}_{186}-\mathrm{Cl} . \mathrm{M}_{\mathrm{n}}=26140 \mathrm{~g} / \mathrm{mol}(\mathrm{dn} / \mathrm{dc}=0.113) ; \mathrm{Ð}=1.10$.

Ts-P $t \mathrm{BMA}_{53}-b-\mathrm{PS}_{13}-\mathrm{Cl} . \mathrm{M}_{\mathrm{n}}=9120 \mathrm{~g} / \mathrm{mol}(\mathrm{dn} / \mathrm{dc}=0.100) ; \mathrm{Ð}=1.45$.

Ts-P $t \mathrm{BMA}_{53}-b-\mathrm{PS}_{16}-\mathrm{Cl} . \mathrm{M}_{\mathrm{n}}=9340 \mathrm{~g} / \mathrm{mol}(\mathrm{dn} / \mathrm{dc}=0.104) ; \mathrm{Ð}=1.42$.

Ts-P $t \mathrm{BMA}_{53}-b-\mathrm{PS}_{97}-\mathrm{Cl} . \mathrm{M}_{\mathrm{n}}=17850 \mathrm{~g} / \mathrm{mol}(\mathrm{dn} / \mathrm{dc}=0.131) ; Đ=1.25$. 
(d) Synthesis of (Ts-PtBMA-b-PS) arms-PDVB ${ }_{\text {core }}$ star-block copolymers. The procedure was similar to those used for the preparation of the first block and diblock macroinitiators. Only the synthesis of the star-block copolymer generated from Ts-P $t \mathrm{BMA}_{30}-b-\mathrm{PS}_{19}-\mathrm{Cl}$ (CCS-1) will be described in detail. In a dry round bottom Schlenk flask equipped with a stirrer bar were introduced $\mathrm{CuBr}(89.9 \mathrm{mg}, 0.61 \mathrm{mmol}), \mathrm{CuBr}_{2}(15.3 \mathrm{mg}, 0.07 \mathrm{mmol})$, PMDETA (150 $\mu \mathrm{L}, 0.68$ $\mathrm{mmol})$ and dry toluene $(10 \mathrm{~mL})$. After 20 minutes of stirring at room temperature, a separately prepared solution of Ts-P $t \mathrm{BMA}_{30}-b-\mathrm{PS}_{19}-\mathrm{Cl}(4.3 \mathrm{~g}, 0.68 \mathrm{mmol})$ and DVB (2 mL, $\left.13.6 \mathrm{mmoles}\right)$ in $10 \mathrm{~mL}$ of dry toluene was added. After three freeze-pump-thaw cycles, the Schlenk flask was immersed in a preheated thermostated oil bath at $80^{\circ} \mathrm{C}$ for $36 \mathrm{~h}$. The flask was then removed from the oil bath and rapidly cooled down to room temperature and the reaction mixture was successively diluted and filtered on alumina columns. The star polymer was recovered as described in the previous sections. $\mathrm{M}_{\mathrm{n}}=106200 \mathrm{~g} / \mathrm{mol}(\mathrm{dn} / \mathrm{dc}=0.182) ; \mathrm{Ð}=1.65$. After deconvolution of the SEC dectector traces (both MALLS and RI traces were analyzed, see Results and Discussion section), two Gaussian distributions were fitted in order to calculate the fractions of both linear and star polymer. The arm to star yield is reported in Table 2. The procedure used for the synthesis of CCS-4 and CCS-5 differed: a double amount of $\mathrm{CuBr}, \mathrm{CuBr}_{2}$ and PMDETA equivalents relative to the macroinitiator was used and the heating was prolonged to $36 \mathrm{~h}$. The data for all isolated samples are reported in Table 2.

\section{Polymerizations. 2. Acrylate systems.}

(a) Synthesis of the $\mathrm{CH}_{3} \mathrm{CH}(\mathrm{COOMe})-\mathrm{PtBA} \mathrm{B}_{40}-\mathrm{Br}$ macroinitiator. In a dry round bottom Schlenk flask equipped with a stirrer bar were introduced $\mathrm{CuBr}(146.4 \mathrm{mg}, 1 \mathrm{mmol}), \mathrm{CuBr}_{2}(22.4$ mg, $0.1 \mathrm{mmol})$, PMDETA $(215 \mu \mathrm{L}, 1 \mathrm{mmol})$, dry toluene $(15 \mathrm{~mL})$ and dodecane. After 20 minutes of stirring at room temperature, $t \mathrm{BA}(10.5 \mathrm{~mL}, 70 \mathrm{mmol})$ and the initiator methyl-2bromopropionate $(250 \mu \mathrm{L}, 1 \mathrm{mmol})$ were injected using argon purged syringes. After three freeze-pump-thaw cycles, the Schlenk flask was placed in a preheated and thermally regulated oil bath at $80^{\circ} \mathrm{C}$. The polymer was recovered as described in the previous sections. Yield: $7 \mathrm{~g}$ $(60 \%) . \mathrm{Mn}_{\mathrm{SEC}}=5310 \mathrm{~g} / \mathrm{mol} ; \mathrm{Ð}=1.15$.

(b) Synthesis of the $\mathrm{CH}_{3} \mathrm{CH}(\mathrm{COOMe})-\mathrm{Pt} \mathrm{BA}_{40}-b-\mathrm{PS}_{31}-\mathrm{Br}$ macroinitiator. This procedure is similar to those described in the methacrylate section. From $5.3 \mathrm{~g}(1 \mathrm{mmol})$ of $\mathrm{CH}_{3} \mathrm{CH}(\mathrm{COOMe})-\mathrm{P} t \mathrm{BA}_{40}-\mathrm{Br}$ and $4.7 \mathrm{~mL}(40 \mathrm{mmol})$ of styrene in $18 \mathrm{~mL}$ of toluene, $\left.\mathrm{CH}_{3} \mathrm{CH}(\mathrm{COOMe})-\mathrm{P} t \mathrm{BA}_{40}-b-\mathrm{PS}_{31}-\mathrm{Br} \mathrm{M}_{\mathrm{n}}=8620 ; \mathrm{D}=1.30\right)$ was synthesized in the presence of $\mathrm{CuBr}(292.8 \mathrm{mg}, 2 \mathrm{mmol})$ and PMDETA $(215 \mu \mathrm{L}, 1 \mathrm{mmol})$.

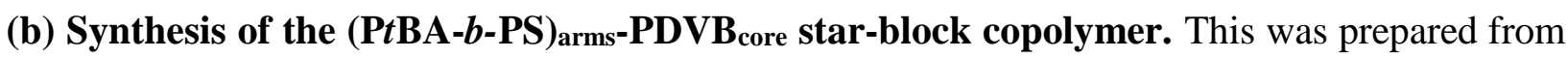
$4 \mathrm{~g}(0.46 \mathrm{mmol})$ of $\mathrm{CH}_{3} \mathrm{CH}(\mathrm{COOMe})-\mathrm{P} \mathrm{BA}_{40}-b-\mathrm{PS}_{31}-\mathrm{Br}$ as macroinitiator using $2 \mathrm{~mL}$ (13.6 
$\mathrm{mmol}$ ) of DVB in $30 \mathrm{~mL}$ of toluene. It was recovered after $72 \mathrm{~h}$ of reaction in the presence of CuBr (135 mg, $0.92 \mathrm{mmol})$, and PMDETA $(198 \mu \mathrm{L}, 0.92 \mathrm{mmol}) . \mathrm{Mn}_{\mathrm{SEC}}=213100 \mathrm{~g} / \mathrm{mol}(\mathrm{dn} / \mathrm{dc}$ $=0.099) ; Ð=1.42$.

Polymer Hydrolyses. The hydrolyses of the tert-butyl ester groups on the methacrylate and acrylate copolymers were carried out as follows. To a round-bottom flask were added $6 \mathrm{~mL}$ of dichloromethane $\left(\mathrm{CH}_{2} \mathrm{Cl}_{2}\right)$ and $300 \mathrm{mg}$ of polymer (PtBMA-X, PtBA-X, diblock copolymer or star polymer). After cooling to $0^{\circ} \mathrm{C}, 0.9 \mathrm{~mL}(11.7 \mathrm{mmol})$ of $\mathrm{CF}_{3} \mathrm{COOH}$ (trifluoroacetic acid) were slowly added from a dropping funnel to the vigorously stirred solution. The reaction mixture was kept at $0^{\circ} \mathrm{C}$ for $3 \mathrm{~h}$, then overnight at room temperature, a precipitate was observed and residual solvent was removed under reduced pressure. The final product was obtained by washing this residue with dichloromethane followed by drying under vacuum.

Ionization. Preparation of the polymer solutions. For each experiment, $30 \mathrm{mg}$ of linear diblock or star-block copolymer was added to $100 \mathrm{~mL}$ of a $0.4 \mathrm{M}$ aqueous solutions of $\mathrm{K}_{2} \mathrm{CO}_{3}$. The $\mathrm{pH}$ of all solutions was above 7 (complete neutralization of the methacrylic and acrylic acid units). The samples were heated for $45 \mathrm{~min}$ at $70^{\circ} \mathrm{C}$ under vigorous stirring to complete the solubilization. At this stage, the acrylic acid units are in the potassium salt form. ${ }^{[28]}$

Atomic force microscopic studies. AFM images were obtained in tapping mode with a NSCRIPTON DPN Writer (Nanoink, USA) at ambient temperature and humidity. AppNano silicon probes (Applied NanoStructures, Inc. Santa Clara, CA, USA) with a nominal spring constant of $40 \mathrm{~N} / \mathrm{m}$ and a nominal resonance frequency of $300 \mathrm{kHz}$ were used. These cantilevers are $125 \mu \mathrm{m}$ long and a tip radius of 5-10 $\mathrm{nm}$. The lateral scan frequency was $0.2 \mathrm{~Hz}$. The images were digitalized by using Nano-R AFM software supplied by Pacific Nanotechnology (USA). For AFM analysis polymers were dispersed in acetone or in tetrahydrofuran (THF) (2 mg of polymer in $2 \mathrm{~mL}$ of solvent), then polymer films were cast by spin coating on silicon substrates, with initial acceleration of $70 \mathrm{rpm} / \mathrm{s}^{2}$ and speed of $1500 \mathrm{rpm} .^{[37]}$ Silicon substrates were previously cleaned in a distilled water ultrasound bath. The root-mean-square roughness $\left(\mathrm{R}_{\mathrm{rms}}\right)$, which is the standard deviation of measured data on the analyzed surface, was calculated according to the following equation:

$R_{r m s}=\sqrt{\frac{\sum_{n=1}^{N}\left(z_{n}-\bar{z}\right)^{2}}{N}}$

where $\bar{z}$ is the average mean of measurements heights and $\mathrm{N}$ is the number of points included in the analyzed surface. 


\section{Acknowledgement}

We are grateful to the CNRS (Centre National de la Recherche Scientifique), the ANR (Agence Nationale de la Recherche, Program BIPHASNANOCAT), Yannick Coppel and Christian Bijani for the NMR-DOSY data treatment and the IUF (Institut Universitaire de France) for financial support. A. Carletto thanks the Politecnico Milano for an Erasmus fellowship and A. F. Cardozo thanks the PRES Toulouse for a Ph.D. fellowship.

\section{References}

[1] H. F. Gao, K. Matyjaszewski, Progr. Polym. Sci. 2009, 34, 317-350.

[2] M. Ranger, M. C. Jones, M. A. Yessine, J. C. Leroux, J. Polym. Sci., Polym. Chem. 2001, 39, $3861-3874$.

[3] G. Kreutzer, C. Ternat, T. Q. Nguyen, C. J. G. Plummer, J. A. E. Manson, V. Castelletto, I. W. Hamley, F. Sun, S. S. Sheiko, A. Herrmann, L. Ouali, H. Sommer, W. Fieber, M. I. Velazco, H. A. Klok, Macromolecules 2006, 39, 4507-4516.

[4] Y. Q. Tang, S. Y. Liu, S. P. Armes, N. C. Billingham, Biomacromolecules 2003, 4, 1636-1645.

[5] H. F. Gao, K. Matyjaszewski, Macromolecules 2008, 41, 1118-1125.

[6] H. F. Gao, K. Matyjaszewski, Macromolecules 2006, 39, 3154-3160.

[7] M. Ouchi, T. Terashima, M. Sawamoto, Chem. Rev. 2009, 109, 4963-5050.

[8] S. Karanam, H. Goossens, B. Klumperman, P. Lemstrat, Macromolecules 2003, 36, 3051-3060.

[9] K. Matyjaszewski, D. A. Shipp, J. L. Wang, T. Grimaud, T. E. Patten, Macromolecules 1998, 31, 68366840.

[10] G. G. du Sart, R. Rachmawati, V. Voet, G. A. van Ekenstein, E. Polushkin, G. ten Brinke, K. Loos, Macromolecules 2008, 41, 6393-6399.

[11] M. Bednarek, T. Biedron, P. Kubisa, Macromol. Chem. Phys. 2000, 201, 58-66.

[12] V. Percec, B. Barboiu, Macromolecules 1995, 28, 7970-7972.

[13] K. Matyjaszewski, Y. Nakagawa, S. G. Gaynor, Macromol. Rapid Comm. 1997, 18, 1057-1066.

[14] H. F. Gao, S. Ohno, K. Matyjaszewski, J. Am. Chem. Soc. 2006, 128, 15111-15113.

[15] J. Burdynska, H. Y. Cho, L. Mueller, K. Matyjaszewski, Macromolecules 2010, 43, 9227-9229.

[16] T. K. Goh, S. Yamashita, K. Satoh, A. Blencowe, M. Kamigaito, G. G. Qiao, Macromol. Rapid Comm. 2011, 32, 456-461.

[17] C. S. Johnson, Progress in Nuclear Magnetic Resonance Spectroscopy 1999, 34, 203-256.

[18] E. J. Cabrita, S. Berger, Magnetic Resonance in Chemistry 2001, 39, S142-S148.

[19] M. A. Delsuc, T. E. Malliavin, Analytical Chemistry 1998, 70, 2146-2148.

[20] E. Durand, M. Clemancey, A. A. Quoineaud, J. Verstraete, D. Espinat, J. M. Lancelin, Energy \& Fuels 2008, 22, 2604-2610.

[21] K. A. Davis, K. Matyjaszewski, Macromolecules 2000, 33, 4039-4047.

[22] X. Zhang, J. H. Xia, K. Matyjaszewski, Macromolecules 2000, 33, 2340-2345.

[23] K. A. Davis, K. Matyjaszewski, Macromolecules 2001, 34, 2101-2107.

[24] A. C. Greene, J. H. Zhu, D. J. Pochan, X. Q. Jia, K. L. Kiick, Macromolecules 2011, 44, 1942-1951.

[25] K. A. Davis, B. Charleux, K. Matyjaszewski, J. Polym. Sci., Polym. Chem. 2000, 38, 2274-2283.

[26] S. H. Qin, K. Y. Qiu, J. Polym. Sci., Polym. Chem. 2001, 39, 1450-1455.

[27] D. Kiserow, K. Prochazka, C. Ramireddy, Z. Tuzar, P. Munk, S. E. Webber, Macromolecules 1992, 25 , 461-469.

[28] C. Burguiere, C. Chassenieux, B. Charleux, Polymer 2003, 44, 509-518.

[29] L. B. Luo, A. Eisenberg, Langmuir 2001, 17, 6804-6811.

[30] C. W. Brown, G. A. Taylor, J. Appl. Polym. Sci. 1969, 13, 629-635.

[31] M. Morcellet, M. Wozniak, Macromolecules 1991, 24, 745-748.

[32] P. Matejicek, K. Podhajecka, J. Humpolickova, F. Uhlik, K. Jelinek, Z. Limpouchova, K. Prochazka, M. Spirkova, Macromolecules 2004, 37, 10141-10154.

[33] I. W. Hamley, Progr. Polym. Sci. 2009, 34, 1161-1210.

[34] R. S. McLean, B. B. Sauer, Macromolecules 1997, 30, 8314-8317.

[35] A. F. M. Barton, CRC Handbook of Solubility Parameters and other Cohesion Parameters, CRC Press, 2000, pp. 139-162. 
[36] J. K. Oh, C. Tang, H. Gao, N. V. Tsarevsky, K. Matyjaszewski, J. Am. Chem. Soc. 2006, 128, 5578-5584.

[37] G. N. Njikang, L. Cao, M. Gauthier, Macromol. Chem. Phys. 2008, 209, 907-918. 


\section{Table-of-Content Graphics}

$\mathrm{R}_{0} \mathrm{Cl} \underset{[\mathrm{CuX} / \mathrm{L}]}{\stackrel{\mathrm{COOtBu}^{\prime}}{\longrightarrow}} \mathrm{R}_{0} \overbrace{\operatorname{coOtBu}}^{f_{n}^{\mathrm{Cl}}} \stackrel{\mathrm{Ph}_{[\mathrm{CuX} / \mathrm{L}]}}{\longrightarrow}$

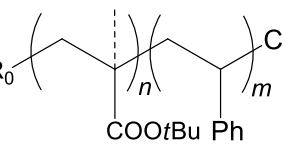
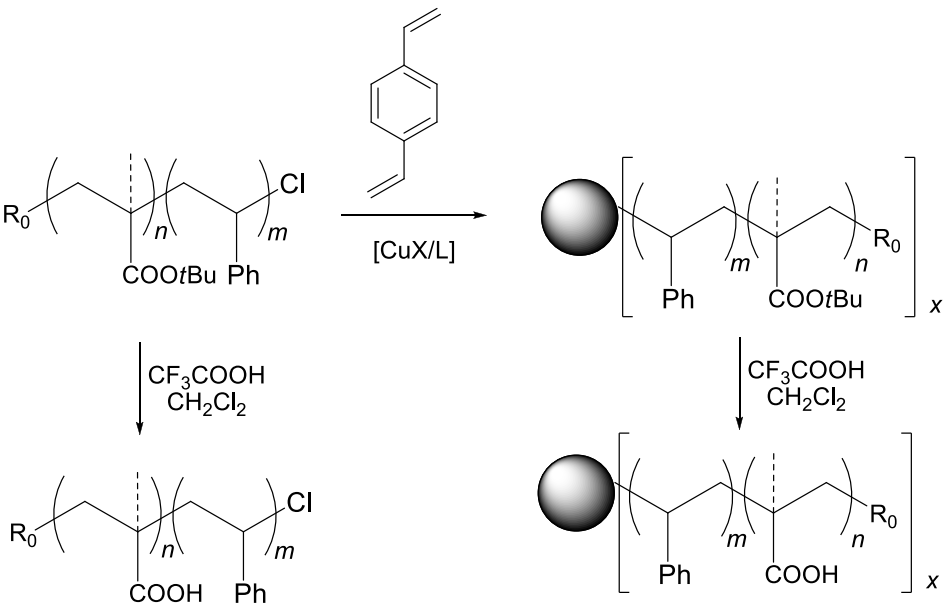

\section{Synopsis}

Amphiphilic core-shell polymers containing a PDVB crosslinked core and PS- $b$-PMAA or PS- $b$ PAA linear arms have been obtained by hydrolysis of the tert-butyl esters of related architectures, assembled in three steps by ATRP. 